\title{
Metro Sistemlerinin Konut Satış Değerine Etkisinin Diğer Faktörler Yönünden Analizi*
}

\author{
Ali Onuralp Ünal ${ }^{1 * *}$, Harun Tanrıvermiş ${ }^{2}$, Yeşim Tanrivermiş ${ }^{3}$ \\ ${ }^{1 * *}$ Dr., EGO Genel Müdürlüğü, Ankara, Türkiye (ORCID: 0000-0002-5816-9939), onuralp_unal@ hotmail.com \\ 2 Prof. Dr., Ankara Üniversitesi, Uygulamalı Bilimler Fakültesi, Gayrimenkul Geliştirme ve Yönetimi Bölümü, Ankara, Türkiye, (ORCID: 0000-0002-0765-5347), \\ tanrivermis@ankara.edu.tr \\ ${ }^{3}$ Doç. Dr., Ankara Üniversitesi, Uygulamalı Bilimler Fakültesi, Gayrimenkul Geliştirme ve Yönetimi Bölümü, Ankara, Türkiye (ORCID: 0000-0002-0859-7150), \\ aliefendioglu@ankara.edu.tr
}

(İlk Geliş Tarihi 22 Temmuz 2021 ve Kabul Tarihi 17 Ekim 2021)

(DOI: 10.31590/ejosat.973834)

ATIF/REFERENCE: Ünal, A.O., Tanrivermiş, H. \& Tanrivermiş, Y. (2021). Metro Sistemlerinin Konut Satış Değerine Etkisinin Diğer Faktörler Yönünden Analizi. Avrupa Bilim ve Teknoloji Dergisi, (27), 636-643.

\section{$\ddot{O} \mathbf{z}$}

Kentlerde konut değerini etkileyen temel parametreler arasında; konum, erişilebilirlik, çevre ve tamamlayıcıllk gibi faktörler yer almaktadır. $\mathrm{Bu}$ çalışma raylı sistemlerin konut fiyatları üzerine etkisini değerlendirmek için yapılmıştır. Araştırma kapsamında Ankara M4 Keçiören Metro Hattı güzergâhında yapılan saha çalışmasının bulguları kullanılarak konut sakinleri yönünden raylı system istasyonlarına erişilebilirlik düzeyi, kira değeri, asansör olma durumu ve oda sayısının konut değerini ne yönde ve ne miktarda etkilediği sonuçları ortaya koyulmuştur. Yapılan araştırma sonucunda kira değeri, asansör olma durumu ve oda sayısının konut değerini pozitif yönde etkilediği görülmüştür. Çalışmanın sonuçlarına göre metro hattının inşa edilip işletmeye açılışından sonraki dönemde konut satış değerlerinde \% 17,40 oranında artışın olduğu gözlemlenmiştir. İncelenen metro hattı istasyonlarının ortalamasına göre istasyona 1 metre yaklaşıldığı zaman konut satış değerinde 168,30 TL artışın olduğu ve konut değerinin ulaşım yatırımından olumlu olarak etkilendiği görülmüştür.

Anahtar Kelimeler: Konut, Değerleme, Ulaşım, Metro.

\section{Analysis of the Effect of Metro Systems on the Sales Value of Housing in Terms of Other Factors}

\begin{abstract}
Location, accessibility, environment and complementarity factors are main parameters affecting housing value in cities. This study is conducted to assess the impact of rail systems on house prices. As part of the research, using the results of a field study conducted on the Ankara M4 Keçiören Metro Line, the results of which affect the level of accessibility to rail system stations, the rental value, the status of elevators and the number of rooms affect the value of the housing in what direction and in what amount are revealed from the point of view of residents. As a result of the research, it is observed that the rental value, the elevator status and the number of rooms positively affect the housing value. According to the results of the study, it is observed that there is a $17.40 \%$ increase in housing sales values in the period after the construction and opening of the metro line. According to the average of the metro line stations examined, when the station is approached by 1 meter, there is an increase of 168.30 TL on the value of housing sales and the value of housing is positively affected by the investment in transportation.
\end{abstract}

Keywords: Housing, Valuation, Transportation, Subway.

\footnotetext{
* Bu makale, Prof. Dr. Harun Tanrıvermiş danışmanlığında tamamlanan "Kamu Ulaşım Projelerinin Gayrimenkul Değeri ve Kullanımına Etkisi: Ankara İli Metro Projesi Örneği” başlıklı doktora tez çalışmasından üretilmiştir.

$1^{* *}$ Sorumlu Yazar: onuralp_unal@ hotmail.com
} 


\section{Giriş}

Birçok ülkede 1950 sonrası dönemde gayrimenkullerin fiziksel ve çevresel özellikleri ve erişilebilirlik ile gayrimenkullerin değerleri arasında güçlü ilişkinin analizine yönelik çalışmaların yapıldı̆̆ı bilinmektedir (Hansen 1959, Martellato vd. 1998, Debrezion vd.2011). Bu çerçevede ulaşım yatırımlarının temel amaçlarının başında kentteki mobilite ve erişilebilirlik düzeyinin artırılması ve pozitif getiri sağlanması gelmektedir. Buna ilave olarak ulaşım sistemi altyapısına yatırımın, kentsel alanlara birçok ekonomik faydaları bulunmakta ve ulaşım olanaklarına bağlı olarak kentsel mekân kullanımı ve gayrimenkullerin değerlerinde önemli ölçüde değişim olmaktadır (Ünal ve Tanrıvermiş 2019).

Kentler için erişilebilirlik, şehirlerin ulaşım akslarının doğru tasarlanmış olmasını ifade etmektedir. Ulaşım aksları ve ulaşım araçları artık insanları sadece bir yerden bir yere ulaştırmanın yanında şehirlerin gelişmesinde ve değişmesinde de büyük önem arz etmektedir. Kentsel alanda ulaşım imkânlarının artması kentteki yoğunluk kademeleri ve alt merkezlerin oluşmasına da sebep olmaktadır. Kentsel alandaki ulaşım altyapı yatırımları şehirlerin sosyo-kültürel ve ekonomik durumunun değişmesine de sebep olmaktadır (Tanrıvermiş 2017, Kartal ve Çorum 2020).

Kentsel ulaşım sistemlerinin geliştirilmesi ve ulaşım modlarının entegrasyonu yoluyla trafikte bekleme süresinde azalış, metro istasyonları etrafında kentsel gelişim (transit oriented development), istihdamda ve gelirde büyüme, erişilebilirlik düzeyinde iyileşme gibi ulaşım ile ilgili çeşitli ekonomik etkiler meydana gelmektedir. Bu çerçevede ulaşım sistemlerindeki yatırımların ekonomik etkilerini ölçebilmek, karar süreçlerinde büyük öneme sahiptir (Yankaya ve Çelik 2005).

Literatürde genel olarak gelişmiş ülkelerin kentlerinde ulaşım sistemleri ve özellikle raylı sistem yatırımlarının gayrimenkul değerleri ve konut piyasalarına etkilerinin analizine ağırlık verildiği görülmektedir. Bu çalışmaların çoğunluğu, raylı sistem ulaşımının, kentsel ulaşım projelerinin en önemli sonuçlarından biri olan gayrimenkulün değeri ve kullanımlarına olası etkilerini incelemiştir (Diaz 1999). Önceki bilimsel çalışmaların sonuçlarına göre toplu taşıma araçları veya metro istasyonlarına yakınlığın, birçok durumda konut ve diğer gayrimenkullerin değerleri ve kira paralarında artışa neden olduğu saptanmıştır (Wardship 2011, Debrezion vd. 2007, Pacheco-Raguz 2010, Ge vd. 2012, Kheyroddin vd. 2014). Türkiye'de bu alanda güvenilir ve doğru veri tabanlarının oluşturulamaması ve kamu sektörünün kararlarının hesap vermekten uzak kurgulanması kentin planlanmasını daha çok fiziksel planlama ile sınırlandırmıştır (Çelik 2003, Yankaya vd. 2005, Ünal vd. 2019).

Ulaşım projelerinin ekonomik etkilerinin ölçülmesi planlama çalışmalarının ana konularından biri haline gelmiş olup, gayrimenkul edinimi ve geliştirme çalışmaları için yer seçiminde de ulaşım, ana değişkenlerden biri olmuştur. Özellikle kamu yatırımlarının başında gelen ulaşım yatırımları, toplumun kalkınması yönünden çok önemli rol oynamakta ve bu yüzden projelerin olası olumlu ve/veya olumsuz etkilerinin sosyal faydamaliyet analizleri içinde ele alınması gerekli görülmektedir. Bu kapsamdaki ulaşım yatırımlarının etkisi; arazi kullanımı, gelir, istihdam ve finansal değerlerde meydana gelen değişimler gibi yönlerden inceleme konusu yapılmaktadır (Yankaya ve Çelik
2005, Tanrıvermiş 2017, Ünal ve Tanrıvermiş 2019, Kartal ve Çorum 2020).

Her bir yerleşim yerinde türlerine göre gayrimenkul piyasalarında; ulaşım yatırımları ve diğer kamu hizmetlerinin etkilerinin gayrimenkul değerlerine etkileri parasal olarak ölçülebilmekte ve bu amaçla Rosen (1974) tarafından hedonik değerleme metodolojisi ile gayrimenkullerin farklı özelliklerinin dolaylı fiyatı veya değere etkisinin tespiti mümkün olmaktadır. Ulaşım olanakları ve yatırımlarının gayrimenkullerin piyasa değerlerine etkilerinin analizinde, matematiksel modeller ve geleneksel değerleme modellerinden yararlanılabilmesi mümkündür (Al-Mosaind vd. 1993, Cervero 1994, Yankaya vd. 2005, Du vd. 2007, Blackledge 2016). Ulaştırma alanında yapılan yatırımlardan kaynaklı erişilebilirlik düzeyinin artışı ve şehrin diğer kısımları ile kurulan bağ nedeni ile söz konusu yatırımın değer oluşturması kaçınılmaz olacaktır. Yapılan yatırımların etkisi; ticari ve konut amaçlı gayrimenkullerin satış veya kira değerlerindeki değişimler ile ölçülebilecek ve bu etkiler; uzun ve kısa vadedeki periyotlar alınarak değerlendirilir olacaktır. Kamu ulaşım yatırımı; hafif raylı hızlı transit, metro ve otoyol gibi ulaşım yatırımları olabilmektedir.

Ahlfeldt (2013) tarafindan The London School of Economics and Political Science Online Research isimli dergide yayınlanan "If We Build It, Will They Pay? Predicting Property Price Effects of Transport Innovations" başlıklı makalede, Londra Metropolitan sınırları içerisinde metro hatlarına 60 dakika yürüme mesafesinde olan konutların diğer konutlara göre \%12 daha değerli olduğu gösterilmiştir.

Hong Kong'da So vd. (1997) tarafindan yapilan ve Journal of Property Valuation and Investment isimli derginin 15. sayısında yayımlanan "Estimating the Influance of Transport on House Prices: Evidence from Honk Kong” başlıklı makalede ise, Hong Kong'da ulaşımın konut fiyatlarına etkisi incelenmiştir. Çalışmada, sadece gayrimenkulün değerine ulaşımın değil başka faktörlerin de etkili olduğu görülmüş ve bu değişkenler üzerinden hedonik model oluşturulmuştur.

Forrest vd. (1996)'nin Journal of Transport Economics and Policy isimli dergide yayımlanan "The Impact of a Light Rail System on the Structure of House Prices: A Hedonic Longitudinal Study" başlıklı makalesinde; Kuzey İngiltere'de bulunan Manchester'da hafif raylı sistemin konut fiyatlarını revize edip etmediğini araştırmışlardır. Araştırma sonuçlarına göre 2.5 milyon nüfuslu şehirde 115 metro istasyonunun etrafinda 19. yüzyıldan itibaren yapılaşmanın yer alması ve 1992'de yeni Metrolink hattının eklenmesiyle konut ve ticari işletmelere bu hatların ekonomik etkilerinin yüksek oranda olduğu görülmüştür.

Ulaşım altyapı yatırımlarının sosyal, ekonomik ve yönetimsel açıdan çok farklı boyutlarda etkileri bulunmaktadır. Ulaşım yatırımlarının toplumun refahı ve kalkınması için yarattığ bu doğrudan etkiler hem teorik, hem de pratik açıdan şehri planlayanları ve kamu yöneticilerini ilgilendirmektedir. Bu nedenle, ulaşım altyapı yatırımlarının muhtemel etkilerinin fayda-maliyet analizlerinde dikkate alınması önemlidir. Karar vericiler için seyahatte geçirilen zamanın etkileri, parametrik esneklikler ve şehiriçi seyahate atfedilen ulaşım değerinin hesaplanmasına imkân tanımaktadır (Yankaya ve Çelik 2005). $\mathrm{Bu}$ yatırımların arazi kullanımı, gelir, istihdam, yoğunluk ve parasal değerlerde yarattığı kısa ve uzun dönemli etkilerinin tespiti, yatırımın gerçekleştirileceği yerin fiziksel ve idari açıdan 
planlanmasının uygulamada yerine getirilmesi için önem arz etmektedir (Gülhan 2018).

"Değer" ve "Erişilebilirlik", ulaşım altyapılarına bireylerin erişmeleri konusunda tartışmaların iki temel kavramıdır. Raylı sistem yatırımı, erişilebilirlik düzeyinde düzelme oluştuğundan ulaşım maliyetini azaltmakta ve kişilerin ulaşım için geçirdiği zamanında azalmasını sağlamaktadır. Diğer taraftan yer seçimi açısından, raylı sistem yatırım güzergâhlarına, hatta istasyonlarına yakınlık, erişim imkânlarının iyileşmesi ve hareketlilik seçeneklerinin artması gibi sağladığı doğrudan ya da dolaylı avantajlar gayrimenkullerin değerinin daha yüksek olacağı beklentisini doğurmakta, gayrimenkul değerleri üzerinde artış yönünde olumlu etkide bulunabilmektedir (Yankaya ve Çelik 2005, Gülhan 2018). Ancak bu teori bütün çalışmalarda doğrulanmamıştır. Raylı sistem yatırımının gayrimenkul değeri üzerindeki etkisini pozitif bulunan çalışmalar olduğu gibi bir kısım çalışmalar ise anlamlı pozitif etkiler bulamamıştır (Yankaya ve Çelik 2005). Pozitif etki, raylı sistem kullanıcısının erişilebilirlik düzeyindeki iyileşmeden faydalanma karşılığ ticari ya da konutlara satın alma amaçlı olarak daha fazla ödeme istekleri şeklinde görülmektedir. Bunun aksine, istasyonların yarattığı gürültü ve suç oranlarında artış gibi etkenlerin ise gayrimenkul değerlerini negatif yönde etkileyebilmektedir. Bu çerçevede çalışma sonuçları ulaşım yatırımlarının konut satış değerlerini hangi yönde / ne derece etki ettiğini araştırmakta ve bu etkilerin gelecek yatırımlarda göz önüne alınması öngörülmektedir.

Bu çalışma üç ana bölümden oluşmakta olup, birinci bölüm olan "Giriş" bölümünde problem tanımlanmış ve aynı konudaki litereatür özetlerine yer verilmiştir. İkinci bölüm olan "Materyal ve Metot" bölümünde problemin çözüm aşamaları detaylandırılmış, saha çalışmasının yöntemi belirlenmiş ve kurulan matematiksel model açıklanmıştır. Üçüncü bölüm olan "Araştırma Sonuçları ve Tartışma" bölümünde ise yapılan çalışmanın sonuçları açıklanmış, konuyla ilgili diğer çalışmaların sonuçları ile kıyaslanmış, sorun ve çözüm önerilerine yer verilmiştir.

\section{Materyal ve Metot}

Araştırmada hedef kitle, Ankara İli Keçiören ve Altındağ İlçelerinden geçen M4 Metro Hattı duraklarının yakın çevresindeki konut sakinleridir. Çalışma kapsamında, metro istasyonu çevresine birbiri ile kesişmeyecek şekilde $370 \mathrm{~m}$ yarı çapında çemberler çizilmiş ve bu çemberler içerisinde 698 anket yapılmıştır. Araştırmada sistematik ve tabakalı örneklem modeli kullanılmıştır. Araştırmanın coğrafi kapsamını Ankara İli metropoliten alan sınırları içinde yer alan Keçiören ve Altındağ İlçe sınırları içerisinde yer alan M4 Keçiören Metro Hattı Projesi ve çevresi oluşturmaktadır.

Çalışmada konut değerine etki eden değişkenler ve bu değişkenlerin yönü ve büyüklüğü ölçülmeye çalışılmıştır. Bu çemberler içindeki istasyona en uzak konut $370 \mathrm{~m}$ uzaklıktadır. Ancak bu çemberler içerisinde tür bakımından birçok gayrimenkul bulunmaktadır. Bu çemberler teker teker ele alınarak içerisindeki konutlar adresleriyle birlikte belirlenmiş ve listelenmiştir. Nihai anket uygulaması ve sahadan veri toplanmasında 22 araştırmacı 6 gün boyunca görev yapmıştır. Her günün sonunda raporlama yapılmış, anketlerin yapıldığ günün ertesi günü uygulama gerçekleştirilen anketlerin telefon kontrolleri yapılarak sağlıklı veri toplanması sağlanmıştır. Sahada uygulama sırasında yapılan kontrollere ek olarak yapılan e-ISSN: 2148-2683 telefon kontrolleri her anketörün uyguladığı anket sayısının \% 10'una uygulanmıştır. Konut sakinlerine uygulanan anket tamamlandıktan sonra istasyon ismi haritaya göre ve istasyona olan uzaklığına göre sıralı olarak hazırlanmıştır.

Saha çalışması aşamasında anket ile toplanan veriler, IBM SPSS Statistics Version 20 paket programı kullanılarak analiz edilmiştir. Model oluşturma sürecinde bir değişkenin diğer değişkenler üzerindeki etkisini ölçmek amacıyla lineer regresyon kullanılmıştır. Bağımlı değişken olarak incelenen konut sakini görüşlerine göre konut satış değerinin logaritması, normal dağılımda yapılan One Sample Kolmogoro-Smirnov testinden anlaşılmıştır. Nominal değişkenlerin grupları arasındaki ilişkiler incelenirken Ki-Kare analizi uygulanmıştır. Normal dağılımdan gelmeyen değişkenler arasındaki ilişkiler incelenirken Spearman's Korelasyon Katsayısından yararlanılmıştır. Bu sayının 2 civarında çıkması otokorelasyonun olmadığını göstermiştir. Ayrıca modelde Harvey ve Glejser değişen varyans testleri yapılmış olup değişen varyans söz konusu olmadığı görülmüştür. Yapılan analizlerin sonuçları bir bütün olarak değerlendirilerek bulguların yorumlanması ve söz konusu bulgulara göre genelleme yapılması yoluna gidilmiştir. Verilerin normal dağılmadığ tablolarda bağımlı iki örnek arasındaki farkın anlamlılığını test etmek için Wilcoxon Testi kullanılmıştır.

Ekonometrik modellere dayanan araştırmaları baz alan iktisat teorisi, iktisadi değişkenler arasındaki ilişkilerin doğru tespit edilebilmesini gerektirmektedir. Ekonometrik modellerde genel olarak, modelin sağındaki değişken bağımsız değişken, sol tarafındaki değişken ise bağımlı değişken olarak isimlendirilir. Ekonometrik modellerin en büyük özelliği hata terimi içermeleridir (Çil 2010). Konut sakini görüşlerine göre metro açıldıktan sonra güncel konut satış değerleri üzerinde hedonik model analizinde; metro açıldıktan sonraki konut satış değerlerine hangi değişkenlerin etki ettiğine dair yapılan analizde konut satış değerlerinin logaritması alınarak işlem yapılmıştır. Konut satış değerlerinin logaritması bağımlı değişken olarak incelenmiştir. Kira değeri, asansörün olup olmaması durumu, oda sayısı ve en yakın metro istasyonuna olan mesafe de bağımsız değişken olarak tanımlanmıştır. Yapılan çalışmada hedonik regresyon modeli uygulanmış ve yapılan analizde hataların normal dağılması, değişen varyans sorununun ve otokorelasyon sorunun olup olmadiğına bakılmıştır. Ankette yer alan değişkenlerin, oluşturulması hedeflenen model içinde olması seçiminde "Backward Elimination" yöntemi kullanılmıştır.

Gayrimenkul çalışmalarında demografik yapı ve değişimin analizi, özellikle proje geliştirme ve yatırım kararlarının verilmesinde önemli görülmektedir. Bu bakımdan çalışmanın bu bölümünde anket sonuçlarına göre anketin ilk kısmını oluşturan demografik özellikleri değerlendirilmiştir. Çalışmanın yapıldığı M4 Keçiören Hattı güzergâhının demografik yapısına göre (cinsiyet, eğitim durumu ve yaş gibi) gayrimenkul değeri farklılık göstermektedir. Anketin uygulandığ 1 kişi 1. kişi olarak belirlenmiş ve evdeki diğer bireyler sorulduğunda 2., 3. kişi olarak sırasıyla yazılmıştır. Hane halkı üyelerine ilişkin cinsiyet ve eğitim durumunu gösteren frekans dağılımında anketin uygulandığı ve cinsiyet sorusuna cevap veren kişi sayısı 649'dur (Tablo 1).

1. kişi olarak tanımlanan kitlenin $\% 64,25$ 'i kadın ve $\% 35,75$ 'i erkeklerden oluşmaktadır. Konuttaki 2. kişilerin \%58,01'ini erkek ve \%41,99'unu kadınlar oluşturmaktadır. 
Ailedeki diğer kişilerde kadın erkek oranının dengeli dağılım gösterdiği görülmektedir. Genel olarak bakıldığında anketin uygulandığı kişilerde kadınların yüzdesinin daha fazla olduğu görülmektedir. Ankete katılan kişilerin \% 46,21'inin ilköğretim mezunu olduğu ve çoğunluğu bu eğitim seviyesinde olan kişilerin oluşturduğu görülmüştür. İlköğretim ve üstü eğitim seviyesine sahip kişiler toplam anket uygulanan kişilerin \% 48,97'sini oluşturmaktadır (Tablo 1).

Tablo 1. Araştırmaya katılan kişilerin demografik bilgileri

\begin{tabular}{lcccccc} 
& \multicolumn{2}{c}{1. Kişi } & \multicolumn{2}{c}{ 2. Kişi } & \multicolumn{2}{c}{ 3. Kişi } \\
\cline { 2 - 7 } & Sayl & $(\%)$ & Sayl & $(\%)$ & Sayl & $(\%)$ \\
\cline { 2 - 7 } Erkek & 232 & 35,75 & 333 & 58,01 & 198 & 56,57 \\
\hline Kadın & 417 & 64,25 & 241 & 41,99 & 152 & 43,43 \\
\hline Toplam & 649 & 100 & 574 & 100 & 350 & 100 \\
\hline Okur-yazar değil & 28 & 4,08 & 17 & 2,84 & 18 & 5,17 \\
\hline Ilköğretim & 317 & 46,21 & 244 & 40,8 & 91 & 26,15 \\
\hline Lise ve dengi & 208 & 30,32 & 209 & 34,95 & 85 & 24,43 \\
\hline Lisans & 110 & 16,03 & 112 & 18,73 & 105 & 30,17 \\
\hline Yüksek Lisans / & 18 & 2,62 & 11 & 1,84 & 14 & 4,02 \\
\hline Bir okul & 5 & 0,73 & 5 & 0,84 & 35 & 10,06 \\
\hline Toplam & 686 & 100 & 598 & 100 & 348 & 100 \\
\hline
\end{tabular}

Literatür taramasında da görüleceği üzere, yapılan çalışmaların bazılarında metro istasyonuna 1 metre yaklaşıldığ zaman konut satış değerinin ne kadar değişeceği merak konusudur. Verileri yeterli olan istasyonlarda yapılan çalışmalar neticesinde, istasyona yaklaşılan her 1 metrede konutun satış değeri Dutluk İstasyonu'nda 142,47 TL, Kuyubaşı İstasyonu'nda 3,22 TL ve Şehitler İstasyonu'nda 248,65 TL artmaktadır. Ayrıca Keçiören'de istasyona 1 metre yaklaştıkça konut satış değerinde 168,30 TL artış olduğu görülmüştür (Tablo 2). İstasyona 1 metre yaklaştıkça en fazla değer artışı Şehitler İstasyonu civarında olup, en az değer artışı Kuyubaşı İstasyonu civarında gerçekleşmiştir. $\mathrm{Bu}$ durumun sebebi Kuyubaşı İstasyonu etrafinda daha yoğun yapılaşma olması ve buna bağlı gürültü ve kalabalıktan duyulan rahatsızlı olarak yorumlanmaktadır.

Tablo 2. İstasyona 1 Metre Yaklaştıkça Değişen Konut Fiyatları

Istasyonlar

(TL)

\section{Dutluk} 142,47

\begin{tabular}{cc}
\hline Kuyubașl & 3,22 \\
\hline Sehitler & 248,65 \\
\hline Keçiören Geneli & 168,30 \\
\hline
\end{tabular}

Özünde farklı veya farklılaştırılmış mallara heterojen mal denilir. Heterojen mallar, ölçülebilen özellik vektörü olarak tanımlanmakta olup belirtilen heterojen malların özellikleri sebebiyle arz ve talep yönlerinden farklılık gösterdiği bilinmektedir (Rosen 1974). Bu çerçevede, konut amaçlı gayrimenkul, heterojen bir maldır. Konutun heterojen bir mal olması, bir konut değerini belirleyen değişken sayısının birden fazla olacağı anlamına gelmektedir. Bir konutun fiyatı, konutta bulunan özelliklerin fiyatları toplamına eşittir. Ancak çoğu zaman konutların değerlerini belirleyen bu değişkenler e-ISSN: 2148-2683 fiyatlandırılamamaktadır. $\mathrm{Bu}$ yüzden konutun fiyat analizlerinde hedonik fiyat modeli yöntemi ile konutun sahip olduğu özelliklerin fiyatları belirlenebilmektedir (Kaya 2012).

Son elli yılda gayrimenkul çalışmalarında sıklıkla kullanılan regresyon analizi, değişkenler arasındaki ilişkiyi belirlemek için kullanılan bir istatistiksel teknik olarak bilinir. Regresyon modellerinden elde edilen sonuçlar, daha sonra geleceği tahmin etmek için kullanılabilmekte ve özellikle toplu değerleme (mass valuation) çalışmalarında il, ilçe, mahalle ve köy ve daha alt yerleşimler için taşınmazların türlerine göre modellerin tahmin edilmesi ve uygunluğunun değerlendirilmesinden sonra toplu değerleme çalışmaları için sıklıkla kullanılması zorunlu olmaktadır (Tanrıvermiş 2017). Buna ilave olarak herhangi bir varlığın fiyatı (mülkiyet veya $\mathrm{P}_{\mathrm{i}}$ ) ile özellikleri arasındaki ilişki, hedonik model veya hedonik regresyon olarak adlandirılır (Belniak ve Wieczorek 2017). Hedonik modeller; regresyon analizinden üretilen katsayılar kullanılarak geliştirilmiş olup, buna göre bir varlığın piyasa fiyatı; varlığın her bir somut ve soyut niteliği ile diğer faktörlere bağlı olarak oluşur. Bu amaçla aşağıdaki denklem yazılabilir (Monson 2009):

Piyasa Fiyatı $=f$ (Parasal Olarak Ölçülebilir ve Konut Özellikleri, Konut Değerini Etkileyen Diğer Diş Faktöreler)

Yerel ve ulusal düzeyde gayrimenkul piyasası analizlerinde kullanılan hedonik fiyat modeli tahmininde, konut için hedonik fiyat fonksiyonu kalıbının doğru tespiti amaçlı bağımlı değişken olan konutun güncel fiyatı ile modelde yer alan bağımsız değişkenler (konutun yapım yılı, niteliği, ısınma, asansör, kat adedi, konutun bulunduğu lokasyon, istasyonlara olan mesafe gibi) arasındaki ilişkinin doğrusal olup olmadığının belirlenmesi gerekmektedir.

Hedonik model kurulması ile yapılan regresyon analizinde, bir malın çeşitlilik gösteren özellikleri ile güncel fiyatı arasında ilişki kurularak bu özelliklerin fiyat üzerindeki etkilerinin değerlendirilmesi amaçlanmaktadır. Bu durumda heterojen bir mal olan konut $\left(\mathrm{X}_{1}, \mathrm{X}_{2}, \ldots, \mathrm{X}_{\mathrm{n}}\right)$ özelliklerinden oluşmakta ve buna göre hedonik fiyat fonksiyonu (eşitlik 2.1)'deki gibi hesaplanabilmektedir:

$P(x)=f\left(X_{1}, X_{2}, ., X_{i}, . ., X_{n}\right) ; i=1,2, \ldots, n$

P hedonik fiyat fonksiyonu olup, malın sahip olduğu özelliklerin fiyat üzerindeki etkisini göstermekte, $\mathrm{X}$ ise konutun özelliklerini temsil etmektedir (Ayvaz 2002). Bu çalışmada hedonik fiyat modeline göre konut satış değeri; niteliği, istasyona uzaklığı ve hesaplanan değişkenler gibi dört ana değişken grubu yardımıyla (2.2)'deki formül formuyla açıklanabilir:

$P=f(H, L, \beta, \varepsilon)$

Eşitlik (2.2)'de; P: gayrimenkulün fiyatı, H: gayrimenkulün niteliklerini tanımlayan değişkenler vektörü, L: gayrimenkulün 
istasyona uzaklığını tanımlayan değişkenler vektörü, $\beta$ : hesaplanan değişkenler vektörü ve $\varepsilon$ : rastlantısal hata terimidir.

Konut sakinleri (malikler ve kullanıcılar) ile yapılan anketin sonuçları ile farklı fonksiyon formları kullanılarak tahmin işlemleri yapılmış olup, çalışmada en uygun fonksiyon formunun yarı logaritmik olduğu tespit edilmiştir.

$\operatorname{LnP}=\beta_{0}+\beta_{1} * x_{1}+\beta_{2} * x_{2}+\beta_{3} * x_{3}+\beta_{4} * x_{4}+\beta_{5} * x_{5}+\ldots \ldots . . \beta_{n} *$ $\mathrm{x}_{\mathrm{n}}+\varepsilon_{\mathrm{l}}$

Eşitlik (2.3)'te; P: konutun maliki tarafından beyan edilen piyasa değeri, $\mathrm{X}_{1} \ldots \ldots \ldots \mathrm{X}_{\mathrm{n}}$ : konutun değerini etkileyebilecek her bir özelliği ve $\varepsilon_{\mathrm{i}}$ : hata terimini göstermektedir. Tahmin edilen model kullanılarak konuta ait bağımsız değişkenlerde ortaya çıkan değişimin, bağımlı değişkende yani konutun fiyatında meydan getirdiği değişimler yüzde olarak tespit edilmektedir. Logaritmik doğrusal model yorumlanırken, bağımsız değişkende meydana gelen bir birimlik değişim, bağımlı değişkende ne oranda değişime neden olacağı yorumlanmaktadır (Kaya 2012). Üretim ve fayda çerçevesinde tam doğru bir fonksiyonel kalıb1 belirlemeyi mümkün kılmadığı bilinmektedir (Triplett 2006). Ancak ampirik çalışmalar, logaritmik doğrusal modelin konut piyasalarında yapılan analizler için kullanılabilir nitelikte bulgular ortaya koyduğunu göstermektedir. Bu bakımdan önceki birçok çalışmada hedonik model tahminin yaygın olarak kullanılan fonksiyonel formun logaritmik doğrusal form olduğu görülmektedir (Sands 1993, Diaz 1999, Ortiz 1996, PachecoRaguz 2010, Syabri 2011, Wardship 2011, Ge vd. 2012, Kaya 2012, Zhao vd. 2012, Mathur ve Smith 2013, Kheyroddin vd. 2014). Yapılan çalışma kapsamında tahmin edilen ve raporlanan fonksiyon formu ile modelin değişkenlerinin büyüklük ve işaretlerinin teorik beklentiye uygunluğu ile tahmin gücünün uluslararası değerleme standartlarına uygunluğu da özel olarak değerlendirilmiştir.

Bağımsız değişkenin bağımlı değişkeni ne oranda ve ne yönde açıkladığını ölçmek amacıyla regresyon analizi yapılmıştır. Yapılan analizde "Backward Elimination" yöntemi kullanılarak değişkenlerden hangilerinin konut fiyatları üzerinde ne derece etkisinin olduğu belirtilmiştir. Sonuçları yorumlamada anlamlılık düzeyi olarak 0,05 değeri kullanılmış olup, $\mathrm{p}<0,05$ olması durumunda ilişkinin anlamlı olduğu, $\mathrm{p}>0,05$ olması durumunda da ilişkinin anlamlı olmadığı belirtilmiştir. Tahmin edilen modelin öncelikle ekonomik, ekonometrik ve istatistiksel geçerlilik testleri yapılmış ve tahmin gücü genel olarak değerlendirilmiştir.

Regresyon modeli bir bağımlı ve bir bağımsız değişkenin bulunduğu durumlarda basit doğrusal regresyon, birden fazla bağımsız değişken olduğunda ise çoklu doğrusal regresyon olarak adlandırılmaktadır (Durmuş vd. 2013). Farklılaştırılmış malların özellikleri dikkate alınarak ticarete konu edilen piyasalara hedonik piyasalar, değişik kriterlerin bir fonksiyonu olarak malın piyasada oluşan fiyatına ise hedonik fiyat denmektedir (Temurlenk ve Özelik 2003). Bu çalışmada, regresyon analizi yapılmış ve konut sakini görüşlerine göre güncel fiyat değerleri ve fiyat artış oranları göz önüne alınarak ayrı ayrı analiz edilmiştir.

Durbin Watson testi, hata terimleri arasında otokorelasyon olup olmadığının belirlenmesi amacıyla kullanılmıştır. Durbin Watson istatistiği 0-4 sürekli aralığında değerler alabilir. Pozitif otokorelasyon varsa istatistik değeri sifira yakın, negatif otokorelasyon varsa 4'e yakın ve otokorelasyon yoksa istatistik değerinin 2'ye yakın bir değer alması beklenir (Gamgam ve Altunkaynak 2015). Durbin-Watson test sonucu 2,164 çıkmış olup, bu sonuç modelde otokorelasyon olmadığını göstermektedir. 13 farklı değişkenin etki ettiği bağımlı değişken ise konut sakinlerinin beyanları üzerine ortaya çıkan metro yapıldıktan sonraki değer olarak belirlenmiştir (Tablo 3). Modelin, ön sav olarak kabul edilen "metro yapıldıktan sonra konut değerlerinde artış olmuştur" savinı desteleyip desteklemediği de test edilmiştir. F testi ile anlamlı olmadığ tespit edilen model ve bağımsız değişkenler ile teorik olarak uygun olmadığ1 düşünülen değişkenler elenmiş, logaritmik güncel satış değeri bağımlı değişken olmak üzere kira, asansör, oda ve mesafe bağımsız değişkenleri ile regresyon modellerinin kurulması kararlaştırılmıştır.

Tablo 3. Çalışmada Kullanılan Bakteriler ve İnkübasyon Koşullarl

\begin{tabular}{l|c|c}
\hline Değişken Tanımı & İsmi & Kodu \\
\hline Konut Sakinin Kiracı veya Malik & Mülkiyet & $x_{1}$ \\
\hline Konutun Apartman Dairesinde & Tür & $x_{2}$ \\
\hline Konutta Asansör Olup Olmaması & Asansör & $x_{3}$ \\
\hline Binadaki Toplam Kat Sayısı & Kat Sayısı & $x_{4}$ \\
\hline Konutun Apartmanda Bulunduğu & Kat & $x_{5}$ \\
\hline Konutun Bulunduğu Cephe & Cephe & $x_{6}$ \\
\hline Konutun Yaşı & Yaş & $x_{7}$ \\
\hline Konutun İçinin Yeni Yapılmış Olma & Içi Yapılı & $x_{8}$ \\
\hline Konutun Brüt Alanı & Brüt Alanı & $x_{9}$ \\
\hline Konutun Toplam Oda Sayısı & Oda Sayısı & $x_{10}$ \\
\hline Konutun En Yakın Metro & Metro & $x_{11}$ \\
\hline Konutun Kaliteli Olması Durumu & Kalite & $x_{12}$ \\
\hline Konutun Kira Değeri & Kira & $x_{13}$ \\
\hline
\end{tabular}

İncelenen yatırım alanında yapılan saha çalışmaları ve analiz sonuçlarına göre tahmin edilen en uygun modelin değişkenlerinin işaretleri ve büyüklüklerinin teorik beklentiye uygun olduğu ve tahmin edilen model ile konut piyasa değerinin kestiriminin yapılabileceği saptanmıştır. İncelenen yatırım alanından toplanan verilerle tahmin edilen modelin sonuçları; kira değeri, asansör olma durumu, oda sayısı ve istasyona olan uzaklık çdeğişkenleri yönüyle incelenmiş ve değere ne oranda etki ettiği katsayılarıyla birlikte özet olarak verilmiştir (Tablo 4). 


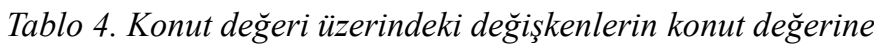
etkileri

\begin{tabular}{|c|c|c|c|c|c|}
\hline \multirow[t]{2}{*}{ Değişkenler } & \multicolumn{2}{|c|}{$\begin{array}{l}\text { Standartlaş- } \\
\text { tırılmamış } \\
\text { Katsayı }\end{array}$} & \multirow[t]{2}{*}{$\begin{array}{l}\text { Standarlaş- } \\
\text { tırılmış kat } \\
\text { sayı }\end{array}$} & \multirow[t]{2}{*}{$t$} & \multirow[t]{2}{*}{$P$} \\
\hline & $\boldsymbol{\beta}_{i}$ & $\begin{array}{l}\text { Standart } \\
\text { Hata }\end{array}$ & & & \\
\hline Sabit & 10,9350 & 0,142 & & 76,941 & 0,000 \\
\hline $\begin{array}{l}\text { Kira } \\
\text { Değeri }\end{array}$ & 0,0005 & 0,000 & 0,329 & 5,826 & 0,000 \\
\hline $\begin{array}{l}\text { Asansör } \\
\text { Olma } \\
\text { Durumu }\end{array}$ & 0,2500 & 0,058 & 0,229 & 4,336 & 0,000 \\
\hline Oda Sayısı & 0,2529 & 0,036 & 0,380 & 6,958 & 0,000 \\
\hline $\begin{array}{l}\text { Ístasyona } \\
\text { Olan } \\
\text { Uzaklık }\end{array}$ & $-0,0003$ & 0,000 & $-0,093$ & $-1,824$ & 0,070 \\
\hline
\end{tabular}

\begin{tabular}{llllll}
\hline Model & $R$ & $R 2$ & $\begin{array}{l}\text { Düzeltilmiş } \\
R^{2}\end{array}$ & $\begin{array}{l}\text { Standart } \\
\text { Hata }\end{array}$ & $\begin{array}{l}\text { Durbin- } \\
\text { Watson }\end{array}$ \\
\hline 1 & 0,691 & 0,477 & 0,467 & 0,24499 & 2,164
\end{tabular}

Çalışmada lineer ve log-lineer formlardan hangisinin kullanılacağı belirlenmiştir. Anket formundaki değişkenlerden anlamlı çıkanlar ile bir model oluşturulmuştur. Belirlenen değişkenler arasında çalışmanın diğer bölümlerinde bahsedilmeyen 'kalite' değişkeni mevcuttur. Konutun belirli bir kalitenin üzerinde olup olmadığı ile ilgili bir analiz yapılmış ve anket uygulanan bütün konutlarda 10 yaşına kadar olan konutlar, içi yapılı olan konutlar ve asansör olan konutlar 'kaliteli' olarak nitelendirilmiş ve bu değişken de analizde kullanılmıştır. Model oluşturmak için tespit dilen bütün değişkenler detaylı olarak değerlendirilmiştir. "Backward Elimination" metodu ile araştırılan ve alternatif olarak değerlendirilen bütün modellerin ve değişkenlerin anlamlılığı incelenmiştir.

Lineer Model:

$\mathrm{P}=\beta_{0}+\beta_{1}{ }^{*}$ mülkiyet $+\beta_{2}{ }^{*}$ tür $+\beta_{3}{ }^{*}$ asansör $+\beta_{4}{ }^{*}$ binanın kat sayıs1

$+\beta_{5}{ }^{*}$ bulunduğu kat $+\beta_{6} *$ cephe $+\beta_{7} *$ yaş $+\beta_{8} *$ içi yapıll $+\beta_{9}{ }^{*}$ brüt alan $+\beta_{10} *$ oda say1s $1+\beta_{11} *$ metro istasyonuna uzakl1k $+\beta_{12} *$ kalite $+\beta_{13}^{*}$ kira $+\varepsilon_{\mathrm{i}}$

$\mathrm{Bu}$ veriler çerçevesinde model oluşturabilmek için en fazla anlamlı sonuç çıkan log-lineer regresyon modeli tercih edilmiştir. $\mathrm{Bu}$ model üzerinde katsayıları anlamsız ve teorik beklentilere uygun olmayan katsayılara ait değişkenler modelden dışlanarak aşağıdaki model elde edilmiştir;

$\operatorname{LnP}(\mathrm{x})=\mathrm{f}\left(X_{1}, X_{2}, X_{3}, X_{4}\right)$

Burada;

$\mathrm{P}(\mathrm{x})=$ Konutun güncel değeri (TL)

$X_{1}=$ Kira değeri (TL)

$X_{2}=$ Asansör olma durumu (0-1)

$X_{3}=$ Oda sayıs1 (Adet)

$X_{4}=$ İstasyona olan uzaklık (m)
Olarak belirlenmiş olup toplam gözlem sayısı 239'dur. Kaynak araştırması ve önceki araştırmaların sonuçlarına göre araştırmada doğrusal fonksiyon formlarının her biri ile ayrı ayrı denemeler yapılmış ve sonunda en uygun bulunan fonksiyon formuna ilişkin sonuçların analizi ve değerlendirilmesi yapılmıştır. Araştırma sonuçlarının raylı sistem ve diğer kentsel altyapı yatırımlarına yönelik projelerin geliştirilmesi ve değerlemesi için karar organları ve uzmanlara yararlı ve yol gösterici olabileceği değerlendirilmiştir.

\section{Araştırma Sonuçları ve Tartışma}

İncelenen yatırım alanında yapılan saha çalışmaları ve analiz sonuçlarına göre tahmin edilen en uygun modelin değişkenlerinin işaretleri ve büyüklüklerinin teorik beklentiye uygun olduğu ve tahmin edilen model ile konut piyasa değerinin kestiriminin yapılabileceği saptanmıştır.

Oluşturulan modelde bağımsız değişkenlerin bağımlı değişkeni açıklama gücü (R Kare) 0,477 olarak hesaplanmıştır. Birimler arası farklılıktan dolayı kira değerine ait katsayı 0,000506 çıkmıştır. Kurulan yarı logaritmik modelde her bir bağımsız değişken için tespit edilen $\beta_{i}$ katsayısı, bağıml değişkeni kendi birimi cinsinden $\% \quad\left(\beta_{i} x 100\right)$ kadar değiștirmektedir. Bu durumda kira değeri değişkeninde meydana gelen bir birimlik değişim konutun satış değerinde pozitif yönde $\%$ 0,05'lik değer değişimine sebep olmaktadır. Asansör olma durumunda meydana gelen değişim konut satış değerinde pozitif yönde \% 25 oranında değer değișimine sebep olmaktadır. Oda sayısının bir birim değişmesi durumunda meydana gelen değişim konut satış değerinde pozitif yönde \% 25,29 oranında değer değişimine sebep olmaktadır. Konutun en yakın metro istasyonuna $1 \mathrm{~m}$ uzak olması durumunda meydana gelen değișim konut satış değerinde negatif yönde \% 0,037 oranında değer değişimine sebep olmaktadır.

Kamu yatırımlarının kentsel büyüme ve gelişim üzerinde etkili olduğu ve hatta tarihsel gelişim sürecinde birçok kentte büyümenin ulaşım akslarına paralel olarak geliştiği görülmektedir. İncelenen proje alanında, metro yatırımı inşa edilerek işletmeye açıldıktan sonra konut satış gelirinde artışın olduğu tespit edilmiştir. Satış değerlerindeki artış oranı \% 17,40 olarak saptanmış olup, maliklerin değer algıları ile model sonuçlarının tutarlılık gösterdiği anlaşılmaktadır. Konut sakini görüşlerine göre metro açıldıktan sonra, metro istasyonuna uzak olan konutların satış değeri \% 17 ve yakın olan konutların satış değeri ise \% 26 artmıştır.

Oluşturulan modele göre kira değeri, asansörü olma durumu ve oda sayısı bağımlı değişkeni pozitif yönde etkilediği görülmüştür. Yapılan araştırma sonucunda kira değeri, asansör olma durumu ve oda sayısının değeri pozitif yönde etkilemesi ve metro istasyonuna olan mesafenin değer ile negatif yönde etkileşim içerisinde olması teorik beklentilere uygun olarak gerçekleştiği görülmüştür. Ekonometrik yöntemlerin yanında, modelde, şehir planlamada kullanılan Mekansal Otokorelasyon'un gücü ölçülmüştür. Günümüzde Mekansal Otokorelasyonu ölçmek için çok sayıda yöntem mevcuttur. Mekansal Otokorelasyon ölçümü için yaygın kullanılan yöntemlerden biri Moran'ın I istatistiğidir (Fischer ve Wang 2011). Mekansal otokorelasyonun testi için GeoDa uygulamasında Moran I testi uygulanmış olup konutun güncel değeri üzerinde kira değeri (TL), oda sayısı (adet), asansör olma durumu (0-1) değişkenleri negatif değer alırken mesafe 
değişkeni poizitif değer aldığı görülmüş ve en güçlü mekânsal otokorelasyonun mesafe değişkeninde sağlandığı anlaşılmıştır.

Ulaşım sistemleri ve arazi kullanımı arasında güçlü bir ilişki bulunmakta ve gayrimenkullerin kullanım biçimleri ve değerlerini etkileyen temel faktörlerin başında erişilebilirlik gelmektedir. Özellikle kentlerde toplu taşıma ve raylı ulaşım sistemlerinin yaygınlaştırılması, yolcu taşıma kapasitesinin artırılmasına olanak vermekte ve gelecek nesillere daha yaşanabilir doğal ve yapılı çevrenin miras olarak bırakılması hedefine ulaşmaya önemli ölçüde katkı yapmaktadır. Bu çalışmada "değer" ve "erişilebilirlik" kavramları vurgulanarak seçilmiş proje örneği çerçevesinde ulaşım sistemleri ve özellikle metro projelerinin konut değerine etkileri irdelenmiştir.

Kent ve yakın çevresinde arazi kullanımı ve ulaşım ilişkileri; 1950'lerden sonra birçok araştırmaya konu olmuş ve erişilebilirliğe bağlı olarak gayrimenkullerin kullanımları ve değerlerindeki değişim analizi yapılmıştır. Öncekilere benzer biçimde bu araştırmada incelenen metro hattının çevresindeki konutların değerlerini etkileyebilen temel faktörlerden birinin de ulaşım sistemlerine olan mesafe olduğu tespit edilmiştir. Ancak ulaşım projelerinin geliştirilmesi ve proje değerleme çalışmalarında mekâna yansımaları ve özellikle projenin neden olabileceği değer artışının ölçülmesi ve bunun fayda-maliyet analizine katılmasının genellikle ihmal edildiği bilinmektedir. $\mathrm{Bu}$ çalışmada; metro yatırımlarının konut satış değerinde meydana getirdiği değişikliğin ortaya konulması ile yatırımların ekonomik ve sosyal etki değerleme çalışmaları ve özellikle sosyal fayda-masraf analizi çalışmaları için önemli bir altlı̆̆ın oluşturulması temel hedef olarak tespit edilmiştir.

Ulaşım projelerinin neden olabileceği konut değer artışının ölçülmesinden sonra değer artışının belirli bir oranının proje finansal modelinde kullanımına yönelik yasal ve kurumsal düzenleme yapılması ve proje finansmanında kullanılabilecek araçların çeşitlendirilmesine gereksinim bulunmaktadır. Belirtilen çalışmaların yapılabilmesi için ulusal, bölgesel ve yerel düzeylerde ulaşım projelerinin türlerine göre neden olabileceği değer artışlarının ölçülmesi, konut değer artışlarının bileşenlerine göre ayrılması ve projelerin finansal modelleme ve risk analizlerin de dâhil belirtilen konularda kapsamlı uygulamalı araştırma projelerinin planlanması ve ulaşım araştırmaları ve lisansüstü eğitim politikalarının yeniden düzenlenmesine ihtiyaç olduğu vurgulanmalıdır. Yatırım projelerinin sabit giderleri, kaynak maliyetleri ve gelir üretme potansiyelleri ile kamu yararı veya daha genel olarak toplum yararı yönlerinden kentsel ulaşım yatırımlarına yönelik politikaların yeniden düzenlenmesine gereksinim olduğu ve makro ve yerel düzeylerde belirtilen biçimde politika değişikliğine gidilmesine gereksinim olduğu ortaya çıkmaktadır. Metro istasyonunua uzaklık mesafe hangi yöntemle ölçülürse ölçülsün, konuta ait diğer değişkenlerle birlikte konutun değerini değiştirdiği anlaşılmıştır. Konut değerine etki eden bütün faktörlerin, o konutun değerini ne derece etkilediğini belirtmek hem metro projelerinin geliştirilmesi, proje değerleme ve proje finansal modelinin tespiti ve uygulanması yönlerinden önem teşkil etmektedir. Bu sebeple yerel ve merkezi idare ile özel kurumların kapsamlı saha çalışmalarına dayalı analizlerin yapılması ve sonuçlarına göre yatırım kararlarının verilmesi zorunlu görülmektedir.

\section{Kaynakça}

Ayvaz, Ö. (2002). Emlak Fiyatlarının Hedonik Model ile Araştırılması: İzmir Örneği. Yüksek Lisans Tezi (basılmamış). Dokuz Eylül Üniversitesi, Sosyal Bilimler Enstitüsü, 151 s., İzmir.

Ahlfeldt, G.M. (2013). If We Build It, Will They Pay? Predicting Property Price Effects of Transport Innovations. Environment and Planning A, 45(8), 19771994.

Al-Mosaind, M.A., Dueker, K.J. ve Strathman, J.G. (1993). Light Rail Transit Stations and Property Values: A Hedonic Price Approach. in: Planning and Programming, Land Use, Public Participation, and Computer Technology in Transportation, Transportation Research Record, 1400(1), 90-94.

Belniak, S. \& Wieczorek, D. (2017). Property valuation using hedonic price method - procedure and its Application, Technical Transactions, 6/2017: 59-70.

Blackledge, M. (2016). Introducing Property Valuation, Routledge, Second Edition, 196, UK.

Cervero, R., (1994). Rail Transit and Joint Development: Land Impacts in Washington, D.C. and Atlanta, APA Journal, Winter, 60(1), 83-94.

Çelik, H.M. (2003). Türk Planlama Sisteminin Dünya Planlama Teorisi İçindeki Yeri ve Açmazları, Planlama Dergisi, 3(4), 93-106.

Çil, N. (2010). Ekonometri Ortak Ders Kitabı. İstanbul Üniversitesi Açık ve Uzaktan Eğitim Fakültesi, 129, İstanbul.

Debrezion, G., Pels, E. ve Rietveld, P. (2007). The Impact of Railway Stations on Residential and Commercial Property Value: A Meta-Analysis. The Journal of Real Estate Finance and Economics, 35(2), 161-180.

Debrezion, G., Pels, E. \& Rietveld, P. (2011). The Impact of Rail Transport on Real Estate Prices: An Empirical Analysis of the Dutch Housing Market, Urban Studies, 48(5): 997-1015.

Diaz, R. (1999). Impacts of Rail Transit on Property Values, Proc. of 1999 Commuter Rail/Rapid Transit Conference.

Du, H. ve Mulley, C. (2007). The Short-Term Land Value Impacts of Urban Rail Transit: Quantitative Evidence From Sunderland. Land Use Policy, 24(1), 223-233.

Durmuş, B., Yurtkoru, S. \& Çinko, M. (2013). Sosyal Bilimlerde SPSS'le Veri Analizi. Beta Yayınevi, 215 s., İstanbul.

Forrest, D., Glen, J. ve Ward, R. (1996). The Impact of a Light Rail System on the Structure of House Prices: A Hedonic Longitudinal Study. Journal of Transport Economics and Policy, 15(1), 15-29.

Fischer, M.M. \& Wang, J. (2011). Spatial Data Analysis: Models, Methods and Techniques. Springer Science \& Business Media, 71, Austria.

Gamgam, H., \& Altunkaynak, B. (2015). Regresyon Analizi. En Küçük Kareler-Değişen Seçme-Regresyon Tanıları, Seçkin Yayıncılik, İstanbul.

Ge, X.J., Macdonald, H. \& Ghosh, S. (2012). Assessing the Impact of Rail Investment on Housing Prices in North-West Sydney. 18th Annual Pacific-RIM Real Estate Society Conference, Adelaide, 15-18 January 2012, Australia.

Gülhan, G. (2018). Raylı Sistem Yatırımlarının Emlak Vergilerine Etkisi ve Mekânsal Değişim Potansiyellerinin Değerlendirilmesi: Kazlıçeşme-Sögütlüçeşme Metro Hattı Örneği. International Journal of Human Sciences, 15(4): 2029-2046. 
Hansen, W.G. (1959). How Accessibility Shapes Land-Use, Journal of the American Institute of Planners. 25(2): 1959.

Kartal, U. \& Çorum, A. (2020). Konut Fiyatını Belirleyen Regresyon Denklemi: Maltepe İlçesi Örneği, Int. J. Adv. Eng. Pure Sci. 2020, 1: 57-67.

Kaya, A. (2012). Türkiye'de Konut Fiyatlarını Etkileyen Faktörlerin Hedonik Fiyat Modeli İle Belirlenmesi, Türkiye Cumhuriyet Merkez Bankası İstatistik Genel Müdürlüğü, Uzmanlık Yeterlilik Tezi, Ankara.

Kheyroddin, R., Taghvaee, A. \& Forouhar, A. (2014). The Influence of Metro Station Development on Neighbourhood Quality. The Case of Tehran Metro Rail System, International Review for Spatial Planning and Sustainable Development, 2(2):64-75.

Martellato, D., Nijkamp, P. \& Reggiani, A. (1998). Measurement and Measures of Network Accessibility: Economic Perspectives, in: K. Button, P. Nijkamp and H. Priemus (Eds) Transport Networks in Europe, Northampton: Edward Elgar, UK, ss.161-182.

Mathur, S. \& Smith, A. (2013). Land Value Capture to Fund Public Transportation Infrastructure: Examination of Joint Development Projects' Revenue Yield and Stability. Transport Policy, 30: 327-335.

Monson, M. (2009). Valuation Using Hedonic Pricing Models, Cornell Real Estate Review, 7: 62-73.

Ortiz, A. (1996). Economic Analysis of Land Value Capture System Used to Finance Road Infrastructure: The Case of Bogotá, Colombia. (Doctoral Dissertation) Available from ProQuest Dissertations and Theses database (UMI No. 9712389), Spain.

Pacheco-Raguz, J.F. (2010). Assessing the impacts of Light Rail Transit on urban land in Manila.

Rosen, S. (1974). Hedonic Pricing and Implicit Markets: Product Differentiation in Pure Competition, Journal of Political Economy, 82(1): 34-55.

Sands, B.D. (1993). The Development Effects of High-speed Rail Stations and Implications for California. The University of California Transportation Center, UCTC Working Paper No. 115. Berkeley, USA.

So, H.M., Tse, R.Y.C. ve Ganesan, S. (1997). Estimating the Influence of Transport On House Prices: Evidence From Hong Kong. Journal of Property Valuation and Investment, 15(1), 40-47.

Syabri, I. (2011). The Influence of Railway Station on Residential Property Values-Spatial Hedonic Approach the Case of Serpong's Railway Station, Jurnal Teknik Sipil, 18 (3): 291-300.

Tanrıvermiş, H. (2017). Gayrimenkul Değerleme Esasları, SPL Sermaye Piyasası Lisanslama Sicil ve Eğitim Kuruluşu, Lisanslama Sınavları Çalışma Kitapları Ders Kodu: 1014 (Konut Değerleme Sinavı, Gayrimenkul Değerleme Sınavı), Ankara.

Temurlenk, M. S. \& Özçelik, A. (2003). Erzurum'da Konut Kiralarının Hedonic Model Yaklaşımıyla İncelenmesi. VI. Ulusal Ekonometri ve İstatistik Sempozyumu 2003. Gazi Üniversitesi, 38; 37-57, Ankara.

Triplett, J. (2006). Handbook on Hedonic Indexes and Quality Adjustments in Price Indexes. Organization for Economic Cooperation and Development, Paris.

Ünal, A.O. \& Tanrıvermiş, H. (2019). Raylı Sistem Projelerinin Gayrimenkul Değerine Etkisi: Ankara İli Keçiören İlçesi M4
Metro Hattı Projesi Örneği, Kastamonu Üniversitesi İktisadi ve İdari Bilimler Fakültesi Dergisi, 21(2):29-55.

Wardship, K. (2011). Public Transit's Impact on Housing Costs: A Review of the Literature. Cetre for Housing Policy, INSIGHTS from Housing Policy Research.

Yankaya U. \& Çelik M. (2005). İzmir Metrosunun Konut Fiyatları Üzerindeki Etkilerinin Hedonik Fiyat Yöntemi İle Modellenmesi. Dokuz Eylül Üniversitesi İktisadi ve İdari Bilimler Fakültesi Dergisi, 20(2); 61-79.

Yankaya U. \& Çelik M. (2007). Kamu Ulaşım Yatırımlarının Gayrimenkul Değerleri Üzerine Etkisinin Modellenmesi: İzmir Metrosu Örneği. İzmir Yüksek Teknoloji Enstitüsü Mimarlık Fakültesi, 258-270.

Zhao, Z., Iacono, M., Lari, A. \& Levinson, D. (2012). Value Capture for Transportation Finance. Procedia - Social and Behavioral Sciences. 48: 435-448. 